\title{
Understanding experiential meaning- making in Chinese adolescent L2 writing: a systemic functional perspective
}

Wenhui Winfred Xuan

\author{
Correspondence: \\ wxuan@hkcc-polyu.edu.hk: \\ winfredhuen@gmail.com \\ Hong Kong Community College, \\ The Hong Kong Polytechnic \\ University, 9 Hoi Ting Road, Yau Ma \\ Tei West Kowloon, Kowloon 00852, \\ Hong Kong, Special Administrative \\ Region of China
}

\begin{abstract}
While most of the $L 2$ writing literature focuses on tertiary L2 writing, there is relatively scanty research conducted with adolescent $L 2$ writers. The present study aims to explore Chinese adolescent L2 writing from the perspective of writing as meaning-making in systemic functional linguistics tradition. Drawing on the framework of process type from systemic functional linguistics, the present study utilizes 500 pieces of texts from ten writing tasks written by a class of 50 Chinese high school students as the data to explore how these adolescent L2 writers deploy process types to instantiate the experiential meaning in their L2 English writing. Findings show that registerial difference exists in the deployment of process type in different writing tasks. In addition, simple, congruent process type is deployed in their writing. Pedagogical recommendations on how to include the system of process type in ESL writing are provided.
\end{abstract}

Keywords: Adolescent L2 writing, Process type, Systemic functional linguistics, Text analysis

\section{Introduction}

In recent years, adolescent L2 writing has seen an exponential growth of research. The body of literature on adolescent L2 writing focuses on various facets of this group of writers, such as identity (Harklau 2011), error analysis (Pennington et al. 1996), genre (Roca de Larios, Martin, and Murphy 2001), technology and internet (Lam 2000), feedback (Lee 2007b), and assessment (Lee 2007a). Despite increased attention on researching adolescent L2 writing, there is relatively limited research on Chinese adolescent L2 writers. Moreover, the bulk of adolescent L2 writing literature so far has relatively little to do with longitudinal perspective.

Writing as meaning-making is a relatively new and emerging perspective from systemic functional linguistics to study writing (Byrnes 2013a, 2013b), where the notion of "meaning-making" is utilized to investigate how language learners are able to deploy the linguistic capital to make meanings in their learning (Ryshina-Pankova 2011). Given the relative lack of knowledge of writing as meaning-making in chinese adolescent L2 writing, a study that investigates Chinese adolescent L2 writing from this perspective can provide us with knowledge on how are Chinese adolescent L2 learners able to deploy their L2 linguistic resources to make meaning in their writing. In addition, such a study also adds some new

(c) The Author(s). 2018 Open Access This article is distributed under the terms of the Creative Commons Attribution 4.0 International License (http://creativecommons.org/licenses/by/4.0/), which permits unrestricted use, distribution, and reproduction in any medium, provided you give appropriate credit to the original author(s) and the source, provide a link to the Creative Commons license, and indicate if changes were made. 
knowledge to L2 writing curriculum design in China and similar EFL contexts, benefitting teachers and learners under similar circumstances.

\section{Literature review}

\section{Adolescent L2 writing studies}

Traditionally, compared with the scholarship in L2 writing, there is a dearth of literature in the field of adolescent L2 writing (Matsuda and De Pew 2002). Ever since 2002, the field of adolescent L2 writing has seen a proliferating increase of studies. Various theoretical lenses, methodologies, perspectives, factors that affect adolescent L2 writing, and aspects have been explored; such as, identity (Harklau 2011), error analysis (Pennington et al. 1996), genre (Roca de Larios, Martin, and Murphy 2001), technology and internet (Lam 2000), feedback (Lee 2007b) and assessment (Lee 2007a). Those different perspectives of adolescent L2 writing studies provide us with abundant findings in understanding this special group of writers. For example, Reynolds (2005) found that adolescent L2 writers would have the idiosyncrasy of making similar grammar mistakes in their writing. The students would spend more time in their writing process (Roca de Larios, Martin, and Murphy 2001), using their mother tongue to think and translate their writing task into L2 (de Courcy 2002), having a lot of grammatical mistakes even after comprehensive instruction (Truscott 1999), and owning a relatively small vocabulary and, thus, expressing less information (Reynolds 2005). When it comes to the studies focusing on this group of writers, adolescent identity is one of the most studied topics. The construction of identity (Harklau 2011) will influence the students' motivation in learning writing, since the students will write differently to express their identity engagement (Lam 2000), use different markers to make themselves sound different (Schoonen and Appel 2005) and even use the internet to develop their social identity (Lam 2000). In terms of teaching and assessment of adolescent L2 writing, teachers' attitudes and methods will impact the instruction (Pennington et al. 1996). Formative assessment is recommended in Hong Kong secondary schools (Lee 2007a), since it will potentially change the teachers' philosophies in providing feedback (Lee 2007b) by not focusing only on errors made, but on how to help students correct them over time. From these findings, we have more research to facilitate our understanding of adolescent L2 writing in terms of text, writers, and teaching and assessment. However, given such mixed findings in the field, there is not much knowledge on how students form their L2 writing, what linguistic resources they use, and how will they use these resources. As Matthiessen states (2006b), learning a language means accumulating different registers in the language to express different meanings appropriately within different contexts. Thus, following such a principle, the present study aims to fill such a gap in the field, hoping to provide more findings and knowledge on how adolescent L2 writers expand their meaning potential by using different linguistic resources. To be more specific, the present study will concentrate on how adolescent Chinese ESL learners deploy process types to construe their experiential meaning in L2 writing.

\section{Studies on writing as meaning-making}

Writing as meaning-making is a relatively new, but ignored, perspective in the realm of L2 writing literature (Byrnes 2013a, 2013b). Meanings could be categorized into three 
types based on the three metafunctions in systemic functional linguistics, which are experiential, interpersonal, and textual meanings (Halliday and Matthiessen 2014). Experiential meanings refer to language that could be utilized to express our human experiences. Interpersonal meanings refer to language that could help us to enact our interpersonal relations; such as, our attitudes, emotions, and modality. Textual meanings refer to language that could be used to organize a coherent and meaningful text. In the tradition of writing as meaning-making, these three strands of meanings are investigated under different contexts with different participants. For example, the construction of theme in advanced L2 writers' book review writing could be an indicator of their mastery in using interactional resources with their imagined readers (RyshinaPankova 2011). The inclusion of the system of modality in L2 writing teaching can facilitate L2 learners to master the modal resources to realize their interpersonal meanings in their writing more accurately and appropriately (Gibbons and Markwick-Smith 1992). In terms of textual meanings, the deployment of macro and hyper themes in writing can actually facilitate students' textual meaning-making, especially in organizing a coherent and cohesive text (Xuan 2015). In addition, the organization of themes in L2 academic writing has registerial differences (North 2005). In terms of experiential meaning-making, the system of transitivity is one of the frameworks that has been most studied. The system of transitivity could be used as a tool in instruction (Martínez 2001), diagnosis (Jiang 2012), enhancement ( $\mathrm{Lu} \mathrm{2012)}$ ) and description (Babaii and Ansary 2005) of ESL academic writing. Martínez (2001) found that the deployment of process types in academic writing can, in fact, indicate whether a writer can adopt an impersonal stance in their academic writing to be a professional writer. Jiang (2012) investigated the conclusion section in MA theses in linguistics written by Chinese linguistics MA students and American linguistics MA students. In her study, she pointed out that significant differences exist in the selection of options from the system of transitivity in the writing of conclusions between native English speakers and non-native speakers. Due to different emphases in the conclusion part written by native and nonnative writers, native English speakers tend to deploy more material processes than the non-native English speakers do. She proposed that application of the transitivity model to the instruction of academic English reading and writing is beneficial and practical because it helps teachers diagnose problems in their students' writing (cf. Gibbons and Markwick-Smith 1992). Lu (2012) found that teaching an ESL writer how to use a relational process in their academic writing will significantly improve their writing in terms of scientificalness. Moreover, the deployment of transitivity in writing book reviews from different disciplines has registerial differences that teachers should pay more attention to when they teach book review writing to different students from different disciplines.

While previous studies mainly focus on L1 or adult L2 learners' writing, there is relatively less research done with adolescent L2 writers. In addition, we have no idea how this L2 writers' group uses transitivity, mainly process type, in their L2 writing to construe their experiential meaning. The present study aims to fill this gap by adding more new knowledge in this field.

With all these gaps left, the following research questions have guided this study:

(1) How do students deploy the system of process type in realizing their experiential meaning potential? 
(2) Does the deployment of different process types reflect registerial differences? How do deployments differ?

\section{Methodology}

Participants

A class of 50 students from a local high school in Guangzhou was recruited as the participants, consisting of 24 boys and 26 girls. The participants' ages ranged from 14 to 16 , attending the last year of their junior high school, which is the last year of the compulsory education in China. They were a class of the best students in Guangzhou according to their academic performance, which was decided by the results of the public exam the students took before entering the junior high school. The participants' English proficiency is at the beginner level, having around 2000 words and mastering the basic grammar rules. They had learnt English for more than five years when they participated in this study. They have a 50-min integrated English lesson every day for five days a week. The lessons basically focus on teaching and learning lexicogrammatical resources (Xuan 2015). There is no explicit writing curriculum in the English curriculum, where the teacher has to teach L2 writing freely as long as her/his L2 writing teaching can facilitate the students to attain a great score in the public exam.

\section{Data collection}

I have collected the participants' writing output in L2 English for two semesters during the last year of their junior high school, which amounted to ten times of writing tasks with 500 pieces of text. The writing tasks were categorized into two major types: an exam writing task and take-home assignments. The exam writing task was completed within a limited time once a month under test circumstances, where the students were given around 30 min to complete the 150-word writing task without using any dictionary or reference during the writing process. The take-home assignment was a writing task that the students were given several days to complete, and they could use a dictionary or reference books to help them with their writing. All the data collected in the present study was from students' natural output, and there was no intervention during the data collection process. I did not either add anything to the daily teaching of the teacher or go to any lesson the students had. Before the data collection, I trained the teacher on how to collect the natural output. In addition, I also shared with the teacher the importance of obtaining the very first draft of the students' writing for the present study. Therefore, all the students' writing was photocopied before giving it back to the students. During the whole year of the data collection, I kept communicating with the English teacher on a weekly basis, ensuring the smoothness of the data collection.

\section{The writing tasks}

Table 1 shows the writing journey that the participants undertook during the two semesters at junior three. As indicated by the table, there were altogether ten writing tasks. Most of the writing tasks were done under exam conditions, i.e. individually, at school and within a set of time limit. However, the first and sixth were take-home assignments. 
Table 1 Ten writing tasks collected for the present study

\begin{tabular}{lll}
\hline Time & \multicolumn{1}{c}{ Topic } & \multicolumn{1}{c}{ Details } \\
\hline 1st & Learn to smile & Advise others to smile \\
2nd & A letter to Mike & Write a letter to a friend, who is sick recently. \\
3rd & Trip to Hangzhou & Sharing your travelling experiences to Hangzhou with your friends. \\
4th & Steve Jobs & Describe Steve Jobs and his life. \\
5th & Lifelong learning & Discuss lifelong learning and how to practice it. \\
6th & An activity & Share an interesting activity. \\
7th & A letter to Alice & Write a letter to Alice and explain how to improve her relationship \\
& & with her Mum. \\
8th & How to be a good learner? & State your views on how to be a good learner. \\
9th & Micro blog & Explore the advantages and disadvantages of micro blog. State your \\
& & views on it. \\
10th & Charity sale & Share the charity sale took place in your school. \\
\hline
\end{tabular}

\section{Data analysis}

All the data collected were in hard copy. I first made sure that all the writing tasks had the students' names and their student numbers on each, ensuring that I could track every student's performance over a longitudinal perspective. I then hired a professional typist to help type those written texts into an electronic version. I trained the professional typist before the massive typing, briefing him on the importance of typing accuracy and also of transferring the exact same script into the electronic version, including students' spelling mistakes, errors, and the wrong words.

Since I collected students' writing tasks ten times with around 500 pieces of texts, I didn't conduct exhaustive clausal analysis with them. Based on my observation of the nature of the writing tasks, I decided to choose the ten best students' writing from the first, the fifth, and the tenth writing tasks as the detailed clausal analysis for the data, yielding 30 pieces of text with about 600 clauses for transitivity analysis. The choice of the three writing tasks was based on the time (the beginning of the data collection, the middle of the data collection and the end of data collection) and the nature of the writing task that these three tasks had already included all the text types the students had written during the whole academic year. The choice of the ten best participants was based on the marking and the performance of these 50 students. I marked the whole class's writing with the teacher according to the marking rubrics of the school, which consisted of content, organization, grammar, and vocabulary (each counts $25 \%$ of the total mark). After that, I checked my marking with the teacher, and we reached agreement on our marking $90 \%$ of the time, making sure that I have chosen the best students in the class. In addition, I went back to the students' learning portfolio to double confirm that the choice was correct.

Once I got the e-copy of the data, I started to identify the clause boundary in the text, based on Halliday and Matthiessen (2014). This included all ranking clauses both finite and nonfinite ones but didn't include rank shifted or embedded clauses. I chose ten samples to do the pilot analysis. I invited one of my colleagues who is also a systemic functional text analysis expert in the field to help. We both analyzed the ten instances of the text and cross checked each other's analysis after that. Our analysis was highly similar, yielding more $93 \%$ similarity, ensuring our analysis was highly consistent. After that, I started to do the massive analysis on my own, based on the texts I had collected. 


\section{Theoretical underpinning: Transitivity model in SFL}

According to Halliday and Matthiessen (2004), transitivity helps construe human experiences into the manageable chunks of process type + participant + circumstance. These different process types, participants and circumstance configure the powerful transitivity system. I will elaborate a little on them in the following section.

\section{Process type}

The system of PROCESS TYPE sorts out our different kinds of experiences into different sub-types of verbs. They construe our experience of different kinds of 'goings-on'. All the verbs in language can be classified into six major process types in English, as we can refer to the grammar in English in Fig. 1 (Halliday and Matthiessen 2004).

As shown in Fig. 1, there are 6 process types in English. According to Halliday and Matthiessen (2004), among the six process types, there are three types that are major ones. They are material, mental and relational processes, while behavioral, verbal and existential are minor ones. Here I will present some examples from the corpus to illustrate different process types in order to demonstrate how data analysis is done with the present study: see Table 2.

\section{Participant}

Every clause is a configuration of a participant and one or more elements involved in it. Participants are directly involved in the process, bringing it about, being affected by it, benefitting from it. In contrast, circumstances are only indirectly involved in the process. Each process type represents a different configuration of process + participants, and participants are labeled according to the nature of the process type. Table 3 shows the different participants in different process types.

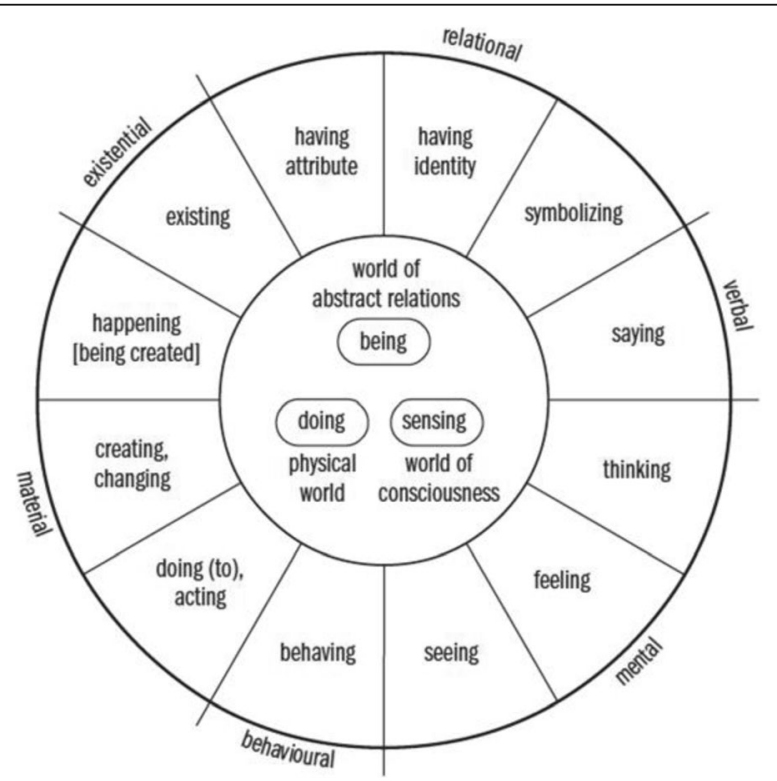

Fig. 1 The grammar of experience: types of process in English (Halliday and Matthiessen 2004: 172) 
Table 2 Process types in English

\begin{tabular}{lll}
\hline Process type & Sub-category & \\
\hline material & event & This morning, our school had a charity sale on the playground. \\
& action & Students brought some pens, notebooks, toys, books and magazines to sell. \\
mental & perception & We may discover that we not only know more about everything, \\
& cognition & Only will we learn those if we have much enough practice in the real society. \\
& emotion & He hates cola. \\
& desideration & I want to have Chinese food. \\
& attributive & Lifelong learning isn't always so easy. \\
relational & identifying & Lifelong learning means that one should never stop learning until death takes \\
& & him away. \\
behavioral & & Henry smiles at his failure. \\
verbal & & She told me the truth. \\
existential & & There is a tree outside.
\end{tabular}

\section{Results and findings}

\section{Research question (1) how do students deploy the system of process type in realizing their experiential meaning potential?}

I will present the overall deployment of process types in the students' writing in Fig. 2.

Figure 2 shows the overall deployment of process types in the students' writing. Of all the three writing tasks I have investigated, I have identified 533 clauses. As Fig. 2 above indicates, by far the most favored process type in the students' writing is 'relational' with a percentage of $48 \%$ (the grammar of having and being). This is followed by 'material' with a percentage of $26 \%$ (the grammar of doing and happening), which is in turn followed by 'mental' with a percentage of $16 \%$ (the grammar of sensing) and 'behavioral' with a percentage of $6 \%$ (the grammar of behaving). 'Verbal' and 'existential' are the two minor types, both with a percentage of $2 \%$.

In order to have a more thorough understanding of the process type composition in different context, I also compared the findings from the present study with the findings from Matthiessen (2006a). Matthiessen (2006a) mapped out the landscape of process type in English by analyzing more than 5000 clauses from different registers in modern English. The comparison findings are shown in Fig. 3.

Figure 2 provides the landscape of the process type distribution in the students' writing in term of number: relational $>$ material $>$ mental $>$ behavioral $>$ verbal $>$ existential.

Table 3 Participants in systemic functional linguistics

\begin{tabular}{llll}
\hline Process type & Nuclear participant & example & Non-nuclear participant \\
\hline material & Actor, Goal & She cooked the rice. & Initiator, Recipient. Client, Scope, Attribute \\
mental & Senser, Phenomenon & She saw the house. & Inducer \\
relational: attributive & Carrier; Attribute & She was strong. & Attributor, Beneficiary \\
relational: identifying & Token, Value & She is the leader. & Assigner \\
behavioral & Behaver (target) & She smiled. & Behaviour, Scope \\
verbal & Sayer (target) & She said. & Receiver, Verbiage \\
existential & Existent & There is a nice pub. & \\
\hline
\end{tabular}




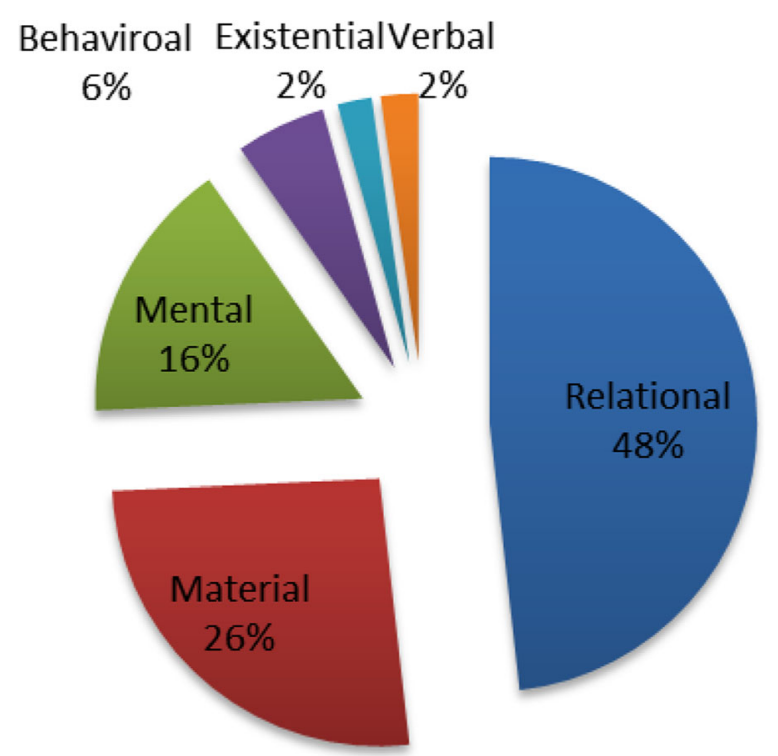

Fig. 2 Overall deployment of process types in students' writing

Combined the findings from Matthiessen (2006a), the present study generated almost the same patterns of process type as Matthiessen' study. However, it is still important to note that relational process is the most dominant type in the present study.

Research question (2) does the deployment of different process types reflect registerial differences? How do deployments differ?

Deployment of process type in different registers

Figure 3 shows the instantiation of process types in the students' writing tasks. We can observe subtler differences by looking at details of each writing task.

Figure 4 shows the deployment of process type in different registers from the students' writing. Globally speaking, different registers present different configurations of process types. Among the six process types, 'relational' is the most

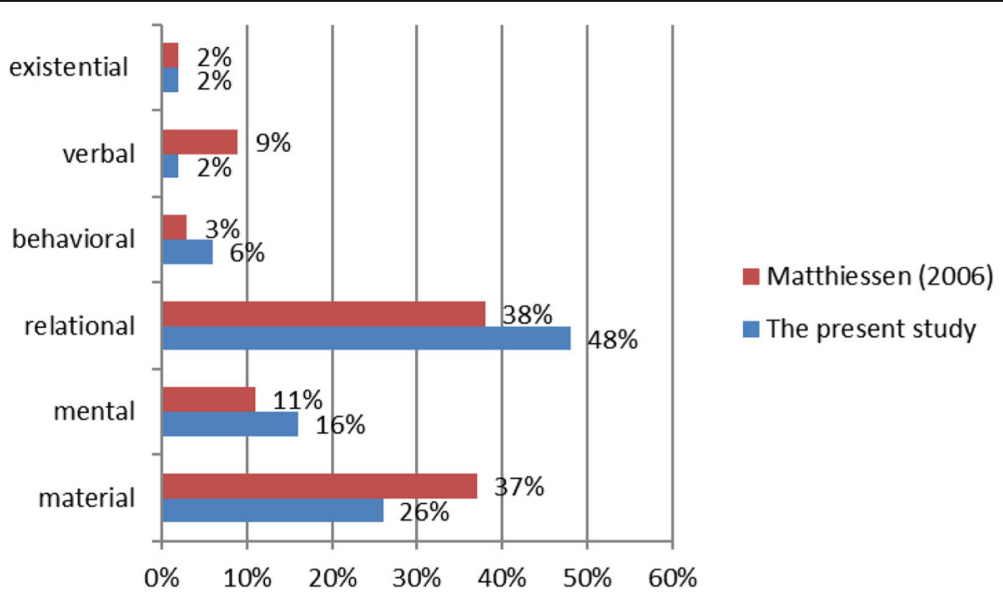

Fig. 3 The comparison of process types in two studies 


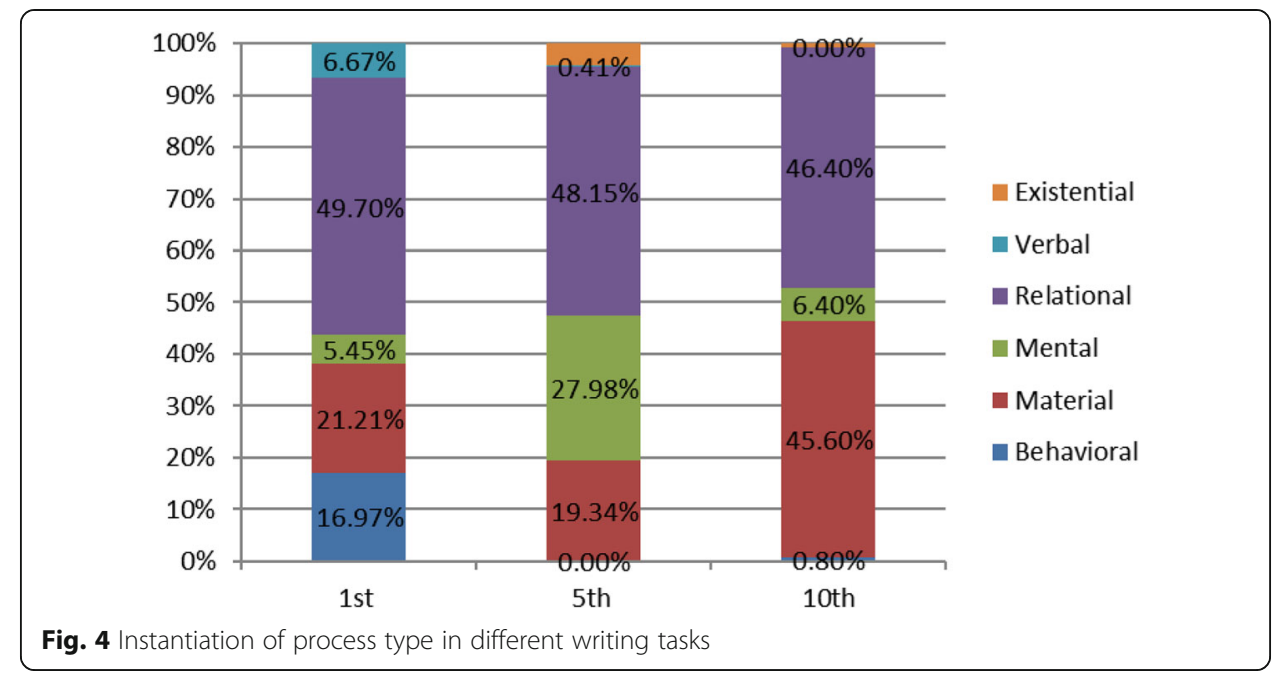

common type in the students' writing, accounting for nearly $50 \%$ of all the process types respectively. Since the 10th writing task is a sharing text, we can note that the students deployed more material processes here than in the other writing tasks - 45.6\%. In the 5th writing task, the students deployed more mental processes, because they needed to express their opinions on lifelong learning and how to practice it. In the 1st writing task, we can see that this is the only writing task in which students deploy behavioral processes. If we look back to the topic, we can find the reason. The topic of the first writing is about smiling. The students deployed many behavioral processes that are related to the behavior of "smiling". Therefore, we can perceive the registerial differences in the configuration of a piece of text through different process type combinations in construing their meaning potentials.

\section{Characterization of process types}

Of all the processes I have identified in the data, I have found that 'relational' is the most common type in the students' writing, while 'material' numbers second and 'mental' numbers third. In this section, I will characterize the major process types by mapping out the landscape of the verbs that the students deployed in their writing. Due to the limited number of verbal and existential processes identified in the present data, I concentrate mainly on relational, material, mental and behavioral processes.

\section{Relational process}

'Relational' is the most dominant process type among the six process types in all the tasks. Of all the 533 clauses I have identified, there are 257 instances of relational process $(48 \%)$. As for writing tasks, two of them are recommending, involving more abstractions and explanations. Therefore, we could expect more relational processes here when the students need to construe their abstractions and explanations in their writing. Based on these 257 cases of relational process, I have conducted a further study to look at the two major types of relational process: attributive and identifying, to investigate how the students used these two types of relational process: see Fig. 4. 
As indicated in Figure 5, most of the relational clauses are attributive relational clauses, $-80 \%$; the remainder are identifying relational clauses $-20 \%$. Compared with the findings in Pun (2011), the students in the present study employed more attributive relational clauses than identifying relational processes. This is probably due to difference in the text types in these two studies. Pun's texts are from chemistry textbooks, where the most important field of activity is that of 'expounding' chemical theory, so we can expect identifying relational clauses to be favored. However, for the present study, the text types are 'recommending' and 'sharing' so there are not so many explanations and identifications in these writing. I will provide some examples of how students use relational clauses in their writing.

(1) Attributive relational clauses.

\begin{tabular}{|c|c|c|c|c|c|c|}
\hline Source & Process & Process type & Medium & Agent & Beneficiary, Range & Circumstance \\
\hline No.1, 1st writing [1] & Is & $\begin{array}{l}\text { relational: } \\
\text { attributive }\end{array}$ & Lifelong learning & & is very important & [Angle:] to us all \\
\hline No.1, 10th writing [10] & was & $\begin{array}{l}\text { relational: } \\
\text { attributive }\end{array}$ & The charity sale & & $\begin{array}{l}\text { such a meaningful } \\
\text { activity }\end{array}$ & \\
\hline No.9, 5th writing [10.1] & Isn't & $\begin{array}{l}\text { relational: } \\
\text { attributive }\end{array}$ & Lifelong learning & & so easy & always \\
\hline
\end{tabular}

As shown by the examples, the students deployed a lot of these attributive relational clauses in discussing their opinions on different cases, like smiling, lifelong learning and charity sale. By selecting these attributive relational clauses, they stated their opinions on these topics, especially in expressing their attitudes.

(2) Identifying relational clauses.

\begin{tabular}{llllll}
\hline $\begin{array}{l}\text { Source } \\
\begin{array}{l}\text { No.6, 5th } \\
\text { writing [4] }\end{array}\end{array}$ & are & $\begin{array}{l}\text { Process type } \\
\text { relational: } \\
\text { identifying }\end{array}$ & $\begin{array}{l}\text { Medium } \\
\text { Visiting museums of variety } \\
\text { and picking worthwhile } \\
\text { books to read }\end{array}$ & $\begin{array}{l}\text { Beneficiary, Range } \\
\text { the first two ways } \\
\text { of lifelong learning }\end{array}$ & \\
$\begin{array}{l}\text { No.9, 5th means } \\
\text { writing [1.0] }\end{array}$ & $\begin{array}{l}\text { relational: } \\
\text { identifying }\end{array}$ & $\begin{array}{l}\text { that one should never stop } \\
\text { learning }\end{array}$ & $\begin{array}{l}\text { Lifelong } \\
\text { learning }\end{array}$ & \\
\hline
\end{tabular}

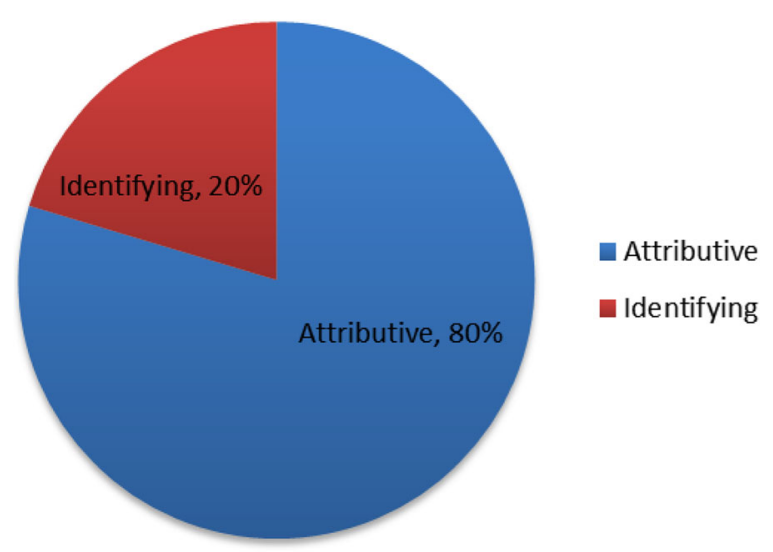

Fig. 5 Overall deployment of the two types of relational processes: attributive and identifying 
When students were required to express or explain some abstract concepts, they tended to deploy identifying relational process as the examples show.

I have also summed up the verbs that students deployed to realize relational processes in their meaning making: see Table 4.

\section{Material process}

'Material' is the second most favored process type in the students' writing- - at $26 \%$. Compared with the other two writing tasks, more material process appeared in the 10th writing task, a 'sharing' text type. Therefore, of all the 139 instances of material processes, there are 57 instances in 10th writing task, while there are 35 and 47 instances in the 1st and 5th writing tasks, respectively. However, most of the processes are realized by common and general verbs in the students writing, such as "go", "help", "brought", "had", "take part in"; the novice writers opt for fairly low-delicacy processes. Furthermore, we can also observe the tendency of the students' deployment of process type to be highly homogeneous. The only explanation I can provide here is that they were taught by the same teacher, used the same materials, wrote the same writing task and had the same limitation of linguistic resources.

Here I will present the verbs list that help realize material process in students' writing: see Table 4 .

\section{Mental process}

Of all the 533 processes, I have identified in my data, 79 cases, or $15 \%$, of them are 'mental'. Surprisingly, most of the mental processes are from writing task 5th. In the other two writing tasks, I only found several instances. As I have mentioned in the previous section, the 5th writing task is about the lifelong learning, inviting the use of vocabulary related to learning and the selection of mental processes to construe the experience of lifelong learning. Under the text type of 'recommending', students are required to present their opinions and suggestions on how to practice lifelong learning. When they need to present their ideas on how to practice lifelong learning, more mental clauses such as "I think" appear in their writing. All these contribute to the increase in mental processes. I will extract cases and demonstrate how students use mental process.

Example one:

(1) Talking learning

[11] Since we can learn about what the places look like with our own eyes.

[12.0] we all know

[12.1] that learning provides us with knowledge.

(No.1 5th Writing)

Table 4 Verbs that contribute to realization of relational process in students' writing

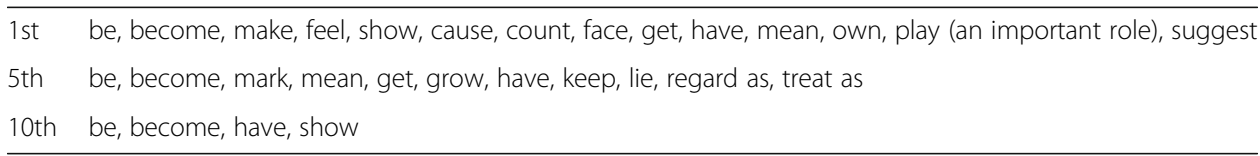


(2) Giving advice

[9.0] If we learn during our whole life,

[9.1] we can know more about the world

[9.2] and understand it better.

(No.4, 5th Writing)

As we can see from the two examples, the students deployed more mental processes in discussing the importance of lifelong learning. These are the typical cases of mental process in this group of students' writing.

I will present the verb list that help realize mental process in students' writing in Table 5 .

As shown in Table 6, under the four sub-types of mental process, cognitive mental process is the most common type. The perceptive and desiderative types are similar in terms of number, while the emotive is the least favored in the students' writing. It is only deployed in the 10th writing with three types of realization.

\section{Behavioral process}

'Behavioral' is a minor process in the students' writing; there are only 29 instances (6\%). However, when I zoom in on these data, I find that most of the behavioral processes are from the first writing task, which is about smiling. In the other two writing tasks, behavioral processes are rare. It is also interesting to observe that most of the Processes in 'behavioral' clauses are realized by the verb "smile". I will show two examples to illustrate.

Example:

(1) [5] People should learn about how to give a smile, a genuine smile. (No.5, 1st writing)

(2) [2] We should learn to smile to ourselves. (No.3, 1st writing)

From this perspective, we are more convinced that not only circumstance is registerial different, so are process types.

\section{Discussion}

\section{Registerial difference}

The transitivity analysis brought out registerial differences among the texts in the different writing tasks. In recommending texts, there are more relational processes than in sharing texts. This finding provides us with a new understanding of adolescent

Table 5 Verbs that realize the Process in 'material' clauses in the students' writing

\footnotetext{
1st accumulate, improve, change, come up, come with, communicate, decrease, depend, fail, fall, find back, fulfill, gain, gather, harvest, increase, live, make, overcome, persist, rebuild, restrain, return, solve, stand, start, try, work out (No. = 28)

5th achieve, benefit, bring, complete, do good to, persist on, finish, fulfill, get, give, go, go out, increase, influence, leave, make, play, provide, push, sit, spend, start, take, teach, use, visit, widen, widespread, write (No. $=29)$

10th buy, hold, keep, bring, devote, do, donate, get, give, go on, help, join, make, provide, sell, take part in, teach $($ No. $=18)$
} 
Table 6 Verbs that realize the Process in 'mental' clauses in students' writing

\begin{tabular}{|c|c|c|c|}
\hline & $1 \mathrm{st}$ & 5th & 10th \\
\hline perceptive & discover, & feel, meet, see, & feel, find, \\
\hline cognitive & $\begin{array}{l}\text { be sure, know, learn, remember, tolerate, } \\
\text { understand, }\end{array}$ & $\begin{array}{l}\text { be sure, focus on, know, learn, read, } \\
\text { remember, study, think, understand }\end{array}$ & expect, be sure, \\
\hline desiderative & want, wish & & hope, wish \\
\hline emotive & & & $\begin{array}{l}\text { enjoy, like, take } \\
\text { pleasure in }\end{array}$ \\
\hline
\end{tabular}

L2 writing. For example, teachers or educators in L2 writing curriculum design could include the system of process type and make these linguistic resources explicit to the students, cultivating them to foster the awareness of registerial difference in the deployment of these linguistic resources. Therefore, instead of exploring the errors or mistakes students have committed in their writing, this new perspective could let us fully understand what they mean with their linguistic resources and generate new knowledge, following writing as meaning-making philosophy.

\section{Unsystematic mastery of the system of process type}

Although the findings do find that there is some registerial difference in process type deployment. Most of the students didn't seem to use sufficient range of process types and delicacy to produce satisfactory text in different registers. 'Relational' is the most frequent process type - particularly in view of what Matthiessen $(1999,2006 \mathrm{a})$ found in registerially mixed samples, where 'relational' and 'material' clauses were roughly equal in frequency. However, among 'relational' clauses, 'identifying' ones, 'attributive' clauses were four times as frequent as 'identifying' ones - $80 \%$ vs. $20 \%$. This finding triggers my reflection on the teaching and assessing of students' learning in terms of process types, especially the instruction and employment of relational process in students' learning. If the students are instructed with these linguistic devices, they would learn better. For example, in teaching identifying relational process, students will know how to use this "formula" to arrange the knowledge and ideas they have learnt and construe the meaning potential they desire to express; while for attributive relational process, they will know how to use this "formula" to describe an item or a thing in our daily lives. Besides, among the four main types of mental processes in Halliday and Matthiessen (2004: 197), I found that 'cognitive' is the most favored type, and the most common verbs of cognition are: "think", "learn" and "remember", with registerial differences. We can see more mental verbs on learning occur in the fifth writing prompt. For this reason, as teacher and educationalist, we can facilitate students' learning journey by creating and providing more different contexts where students can have more opportunities to deploy these resources. In return, this kind of exposure will definitely expand their breadth and depth of the aggregation of different registers (Matthiessen 2006b).

\section{Deployment of low-delicacy process type}

As we can see from the findings, limited numbers of registers developed by the kinds of writing topics given. The deployment of the process type in the present study indicates that the students usually deploy the low-delicacy process type, which shows 
that their active L2 linguistic resources that they can deploy to meaning making is relatively limited. For instance, the deployment of material process is a typical example in the students' writing. After sorting out the material processes that the students have used in their writing, I found that most of the processes are "go", "help", "bring", and "take part in" etc. Those process types are actually quite simple, congruent verbs in writing, which unfortunately constrain their potential of meaning-making. Moreover, the deployment of such process types contributes to their limited abilities in expressing delicate, detailed, and elaborated meaning in their L2 writing. Therefore, the inclusion of process type in the curriculum is highly recommended in such a context, training the students to utilize different process types in writing, and especially to provide a cluster of synonyms from which the students might choose. Such an explicit inclusion and facilitation will foster them to have the awareness of picking up the most appropriate words for their writing instead of using all low-delicacy process type.

\section{Homogeneity of the deployment of process type}

Based on the analysis, I have also found that the deployment of process type in these students' writing is quite homogeneous. Most of the students wrote the same process type and the same structure. I have talked to the teacher who taught them. The teacher explained the reason why they wrote the same text with almost the same ideas, structure, and process types. The major reason of this phenomenon is the macro context of their learning, which is controlled by the exam. The students are required to pass the public exam in order to secure a better position in senior high school. Therefore, most of the writing tasks and assignments in the present study were exambased practice and tests. The students have to follow these successful templates or models from their teachers if they aim to excel in the exam. This exam-driven culture (Xuan 2015, 2017) fundamentally impacts the design of the writing curriculum and the teaching of L2 writing in such a context, which, in return, exploits the students' learning opportunities, contradicting what Matthiessen (2006b) proposed, that learning a language is equal to accumulating different registers to be able to make meaning in the language.

\section{Conclusion}

This article presents the findings of a longitudinal study that demonstrates how the description of the system of process type (e.g. Halliday 1967a, 1967b/8; Halliday and Matthiessen 2004: Ch. 5) can be used to investigate adolescent Chinese ESL learners' writing to bring out their partial mastery and deployment of the resources. Based on the findings and discussion, I have delineated the linguistics features in these students' written text in the system of process type, in order to provide the whole landscape of students' deployment of process types in their writing and throw some light on the design of curriculum and writing teaching at the secondary level in English education in Chinese mainland.

In the system of PROCESS TYPE, the students select numerous 'relational' clauses, which is quite different from what Matthiessen $(1999,2006$ a) found in his registerially varied samples of native speakers' texts. Registerial difference in deployment of process type in students' writing is found. In addition, unsystematic mastery of the system of 
process type is shown in the students' writing, which constrains the students' meaningmaking potential. Besides, the deployment of low-delicacy and homogeneity of process type is found. Limited active L2 linguistic resources and an exam-driven culture explain this phenomenon. The three successive writing tasks are registerially different - the first two being located in 'recommending' contexts, and the last in a 'sharing' context. According to these findings, as writing instructors and researchers, we should present the whole system of process type to our students to equip them with the whole picture (Gibbons and Markwick-Smith 1992), in order to let them make the right choice in expressing themselves experientially.

\section{Limitations}

Despite the in-depth analysis conducted in the present study, the interpretation of the findings should be used cautiously. The analytical framework could be more comprehensive, but only process type. The number of the participants could be more, but not only 50 and from different academic backgrounds, if possible. The present study recruited the best students in terms of academic performance in Guangzhou. The findings could not be generalized to all the schools with different contextual parameters. In addition, the time framework is too short. If possible, a longer time frame would provide us with more insightful and interesting findings.

\section{Acknowledgements}

I would like to extend my heartfelt thanks to my PhD supervisor Prof Christian Matthiessen for his endless support and impeccable supervision.

\section{Funding}

None.

Availability of data and materials

Supporting data is available to editors and peer reviewers as long as there is any request.

Authors' contributions

This paper is a single-authored paper which accomplished by the author himself. The author read and approved the final manuscript.

\section{Competing interests}

There is no non-financial competing interests (political, personal, religious, ideological, academic, intellectual, commercial or any other) to declare in relation to this manuscript.

\section{Publisher's Note}

Springer Nature remains neutral with regard to jurisdictional claims in published maps and institutional affiliations.

Received: 17 October 2017 Accepted: 28 March 2018

Published online: 13 April 2018

\section{References}

Babaii, E., \& Ansary, H. (2005). On the effect of disciplinary variation on transitivity: The case of academic book reviews. Asian EFL Journal, 7(3), 113-126.

Byrnes, H. (2013a). Curricular thinking in language education: Why does it matter? The 4th PolySystemic: Language and Education Symposium. The Hong Kong Polytechnic University: Hong Kong.

Byrnes, H. (2013b). Positioning writing as meaning-making in writing research: An introduction. Journal of Second Language Writing, 22(2), 95-106.

de Courcy, M. (Ed.). (2002). Learners' experiences of immersion education: Case studies of French and Chinese. Buffalo: Multilingual Matters.

Gibbons, J., \& Markwick-Smith, V. (1992). Exploring the use of a systemic semantic description. International Journal of Applied Linguistics, 2(1), 36-49.

Halliday, M. A. K. (1967a). Notes on transitivity and theme in English part I. Journal of Linguistics, 3(01), 37-81.

Halliday, M. A. K. (1967b). Notes on transitivity and theme in English: Part 2. Journal of Linguistics, 3(02), 199-244.

Halliday, M. A. K., \& Matthiessen, C. M. I. M. (2004). An introduction to functional grammar (3rd ed.). London: Arnold.

Halliday, M. A. K, \& Matthiessen, C. M. I. M. (2014). Halliday's introduction to functional grammar (4th ed.). London: Routledge. 
Harklau, L. (2011). Commentary: Adolescent L2 writing research as an emerging field. Journal of Second Language Writing, 20(3), 227-230.

Jiang, W. (2012). A contrastive study of conclusions in English linguistics master theses in terms of transitivity system, Unpublished MA. Jinan: Shandong Normal University.

Lam, E. (2000). L2 literacy and the design of the self: A case study of a teenager writing on the internet. TESOL Quarterly, 34, 457-482.

Lee, I. (2007a). Assessment for learning: Integrating assessment, teaching, and learning in the ESL/EFL writing classroom. The Canadian Modern Language Review, 64(1), 199-213.

Lee, I. (2007b). Feedback in Hong Kong secondary writing classrooms: Assessment for learning or assessment of learning? Assessing Writing, 12(3), 180-198.

Lu, A. (2012). Transitivity shifts in academic writing. Asian EFL Journal, 103, 129

Martínez, I. A. (2001). Impersonality in the research article as revealed by analysis of the transitivity structure. English for Specific Purposes, 20(3), 227-247.

Matsuda, P. K., \& De Pew, K. E. (2002). Early second language writing: An introduction. Journal of Second Language Writing, 11(4), 261-268.

Matthiessen, C. M. I. M. (1999). The system of TRANSITIVITY: An exploratory study of text-based profiles. Functions of Language, 6(1), 1-51.

Matthiessen, C. M. I. M. (2006a). Frequency profiles of some basic grammatical systems: An interim report. In S. Hunston \& G. Thompson (Eds.), System and corpus: Exploring connections (pp. 103-142). London: Equinox.

Matthiessen, C. M. I. M. (2006b). Educating for advanced foreign language capacities: Exploring the meaning-making resources of languages systemic-functionally. In H. Byrnes (Ed.), Advanced instructed language learning: The complementary contribution of Halliday and Vygotsky (pp. 31-57). London and New York: Continuum.

North, S. (2005). Disciplinary variation in the use of theme in undergraduate essays. Applied Linguistics, 26(3), 431-452.

Pennington, M. C., Brock, M. N., \& Yue, F. (1996). Explaining Hong Kong students' response to process writing: An exploration of causes and outcomes. Journal of Second Language Writing, 5, 227-252.

Pun, K. H. (2011). Analysis of Hong Kong science textbooks using systemic functional approach, Unpublished MA thesis. Hong Kong: The Hong Kong Polytechnic University.

Reynolds, D. W. (2005). Linguistic correlates of second language literacy development: Evidence from middle-grade learner essays. Journal of Second Language Writing, 14, 19-45.

Ryshina-Pankova, M. (2011). Developmental changes in the use of interactional resources: Persuading the reader in FL book reviews. Journal of Second Language Writing, 20(4), 243-256.

Schoonen, R., \& Appel, R. (2005). Street language: A multilingual youth register in the Netherlands. Journal of Multilingual and Multicultural Development, 26(2), 85-117.

Truscott, J. (1999). The case for "the case against grammar correction in L2 writing classes": A response to Ferris. Journal of Second Language Writing, 8(2), 111-122.

Xuan, W. (2015). A longitudinal study of Chinese high school students learning English based on systemic functional text analysis (Unpublished Doctoral dissertation). The Hong Kong Polytechnic University: Hong Kong.

Xuan, W. W. (2017). An exploratory study of ESL writing by junior secondary students in China: Text type, register and textual features. Functional Linguistics, 4(1), 3.

Submit your manuscript to a SpringerOpen ${ }^{\mathcal{O}}$ journal and benefit from:

- Convenient online submission

Rigorous peer review

- Open access: articles freely available online

- High visibility within the field

- Retaining the copyright to your article

Submit your next manuscript at $\gg$ springeropen.com 